\title{
Nagel's Criticism Of Physicalism
}

\author{
Dr. Thomas W. Smythe \\ Retired Associate Professor of Philosophy, \\ North Carolina Central University \\ Thomas Evans \\ Department of Language and Literature, \\ North Carolina Central University
}

doi: 10.19044/esj.2016.v12n17p78 URL:http://dx.doi.org/10.19044/esj.2016.v12n17p78

\begin{abstract}
The philosopher Thomas Nagel is well known for being skeptical of the claim that psychological states are purely physical. When physical science gives us a complete description of the world, it leaves out the point of view from which each of us is aware of their perspective on the world. This paper is a critical treatment of Nagel's problem with physicalism. We ignore the vast literature on the self.
\end{abstract}

Keywords: Physicalism, Mental States, Body

Thomas Nagel is skeptical that a purely physical account of a human existence could be completely true. He argues that a person is a subject of mental states, which involves more than materialism can explain. Once one has completely described the physical being of the self, he says, one is left with a self that is also the "subject" of this description:

The problem can be shown to be general in the following way: consider everything that can be said about the world without employing any token-reflexive expressions. This will include a description of all its physical contents and their states. . . It will also include a description of all persons in the world and their histories, memories, thoughts, sensations, perceptions, intentions, and so forth. I can describe without token-reflexives the entire world and everything in it - and this will include a description of Thomas Nagel and what he is thinking and feeling. But there seems to remain one thing I cannot say in this fashion-namely, which of the various persons in the world I am. And when everything that can be said in the specified manner has been said, and the world in a 
sense has been completely described, there seems to remain one fact that has not been expressed, and that is the fact that I am Thomas Nagel. This is the fact that $\underline{I}$ am the subject of these experiences; this body is my body; the subject or the center of my world is this person, Thomas Nagel. (Nagel, 1965)

It follows from this, he continues, that a sensation's "being mine" cannot consist in its being an attribute of any substance, such as a body or even a soul. For "nothing in the specification of that soul will determine that it is me, and that I am that person.” Any substance we pick as the substance of psychological states can be thrown into the objective world. And everything about it is completely described except that I am that person. Nagel concludes from this that the self is not a substance of any sort and that "the special kind of possession which characterizes the relation between me and my psychological states cannot be represented as the possession of certain attributes by a subject” (Nagel, 1965).

Although this argument seems plausible, Nagel's conclusion does not follow because his linguistic analysis cannot show that something has actually been omitted from a physicalistic description of the world or that if it has been, that what is left out is not itself physical. No matter how detailed the token-reflexive-free description is, and no matter in what terms it is couched, such a description cannot possibly say which of the persons in the world I am, or which one anyone else is. The removal of token-reflexive-free expressions in philosophy has been associated with the attempt to create an ideal language which could describe every fact in the world with statements that are not context bound. However, such a cleansing of language would do more than make it impossible for me to indicate which of the people in the world I am. It would make it impossible for me to indicate who others are (which I do in relation to myself), and make it impossible for me to indicate where I am or when I am speaking or thinking with respect to the past, present, or future. Demonstratives, pronouns, and tenses would be eliminated from such a language. But even if we accept such an ideal token-reflexive free physicalistic language, it does not follow either that I am a physical or nonphysical thing. The mere fact that I have been left out of the description of the world has no implications about what sort of thing I am. For I could just add on a physicalistic description of myself. This could lead to an infinite regress for then I would not be able to say that it is my description of myself.

It does not follow, as Nagel says it does, that the subject of experiences cannot be a thing, or that a mental state's being mine cannot consist in its being an attribute of a thing--unless we make a further assumption that for a thing to be what I am, qua subject of experiences, 
something in the specification or description of that thing must determine that it is mine, or which person I am. But this assumption will not work in any other context. There is nothing in a description of a chair that determines that it is this chair rather than some other chair. However, pointing out other contexts where the same point can be made does not remove the difficulty, because this can always be traced back to the use of 'I'. What makes this chair this chair is the fact that it is the chair that $\underline{I}$ am looking at or pointing to. I can pick out which chair 'this chair' refers to for someone else, and they can identify it, because it is anchored to my point of view. Others can understand me because they can understand what I mean by 'this chair' from features of the situation such as my gestures, my use of the pronoun 'I', and the like. The important point here is that my use of 'I' in order to say which person I am talking about has no bearing at all on what sort of thing I am, or whether I am a thing at all, or on whether I am a mental of physical substance or thing. Nor does it have anything to do with the fact that "this body" is my body. What makes my body the particular body it is does not depend on the question of whether my body can be individuated without the use of token-reflexives. It does involve facts such as my feeling something when "this body" has something touching it in part that makes it my body, and this is quite different from what makes my body separate and different from other bodies. Philosophers who claim the pronoun 'I' individuates and has nothing to do with the kind of thing I am sometimes deny that the self is a substance of any kind or a subject of experience. For instance, S. Coval writes that:

Questions such as 'Under what conditions am I a "self" or an "I" ? or 'When am I first-person?' have sometimes been answered in terms of 'consciousness' or 'experience' or 'thinking' or their cognates. But to be an 'I' , or a 'Self', one need only be speaking or using the first person pronoun. . .nothing more. The present performance of speech is the necessary condition for the use of the first person. . . . Only when one is actually in the act of speaking, or its derivatives, is one ever capable of being a 'self' or an 'I.' (Coval, 1966)

Coval holds that the only sense in which one is a subject of experiences occurs when one is the grammatical subject of discourse and, further, only when one is actually speaking. Immanuel Kant said that the 'I think' must be able to accompany all of our representations, and Coval is likewise saying that 'I say' must be able to accompany all of our speech acts, and that this is the only sense in which one is an I, a self, or subject of anything. There is no subject of experiences, but only a subject of discourse, made explicit in first person performances of speech acts. 
However, this way out is too short because it denies that we are people who have thoughts, feelings, and desires. This is all we mean when we say that there is something, some substance, which has and undergoes these mental states. The physicalist is maintaining that it is the same substance that has and undergoes physical states, and this substance is the brain and human body. There are subjects of experience even without the features of the word 'I'.

We may yet feel that something has been left out in a scientific description of the world that does not contain demonstratives or pronouns, even when we allow for the use of token-reflexive words and statements. The suspicion is that our essential subjectivity, the fact that I am a subject of these experiences, that I am the center of my world, can never be captured in the facts about the world. In one sense this sounds absurd, because that there are people having certain experiences and having separate points of view is a fact about the world, just as it is a fact about the world that I am now thinking of this problem. When I consider myself as subject, as the center of my world, I consider myself as occupying a single and unique point of view, and this itself is a fact about the world, but not about my world. There is an important sense in which each person's point of view is unique and singular, giving one a system of reference that has oneself as the center. This explains why we feel that something has been left out of any complete scientific description of the world, for the facts of science do not mention any singular point of view, including my own.

Against Nagel, one can argue that I can always add on a physical description of myself as the person who is writing the description of the world. But that will not solve the problem, for I must leave out the fact it is me who is writing the description. I cannot include in my description of myself the fact that it is my description without being landed in an infinite regress. This is exactly what Gilbert Ryle has called the systematic elusiveness of the 'I.' Ryle talks about higher order acts, which themselves can result in yet another higher order act, and so on. He says that "selfcommentary, self-ridicule, and self-admonition are logically condemned to eternal penultimacy”(Ryle, 1949). I can never catch my innermost self; I am always referring to what I just did or of what I was aware and not the self. In self-awareness I can never tell whether the self is a physical thing or not, but I am aware that I am something, a thing that thinks. This is a reflective act of self-awareness. I am not aware of this thinking thing as being physical or as nonphysical, but just aware that something is doing the thinking (Smythe, 2012).

To return to Nagel, in a physicalistic description of the world, all the points of view are there, but none of them is especially privileged; there is no center. If two or more people set out to write up the same description of the 
world, they will have to leave out any mention of who is writing it, and the 'I' will not appear in the description because 'I' refers to that point of view which constitutes a unique system of reference. This is not to say that one's own conscious center of awareness will be omitted from such a description, and, therefore, amounts to nothing. What is omitted is the fact that it is my conscious center of awareness, even though I am in the world and I am something. It might seem that there is one subject of all experiences (myself), and this is left out of such a description., but there really is no single point of view or privileged self whose point of view is the point of view. Consider some related passages from Wittgenstein in this connection:

5.631 If I wrote a book called The World As I Found It, I should have to include a report on my body, and should have to include which parts were subject to my will, and which were not, etc., this being a method of isolating the subject, or rather of showing that in an important sense there is no subject; for it alone could not be mentioned in that book.

5.632 The subject does not belong to the world: rather, it is the limit of the world. (Wittgenstein, 1921)

Nagel tries to formulate some intuitive discomforts which grow out of a dissatisfaction with physicalism. However, once these misgivings are unpacked they can be seen to be unfounded or the result of confusion. One source of confusion is the suspicion that I cannot possibly be my body because my body is something I own or possess. Once it is seen that that phrases such as "my body" and "my mind" cannot be construed on the model of "my car," the source of discomfort can be dispelled. "My body" seems to refer to something over and above my body, that owns my body, but "my car" does not seem to mislead us that way. It is clear that I am separable from my car, but it is problematic whether I am something separable from my body. Elsewhere I have tried to say what a materialist could say about what makes my body mine (Smythe, 2012). It is to the advantage of a materialist to construe such locutions as "persons owning their bodies" or "the self which possesses this body." These phrases can make it seem that a person cannot be just a physical thing.

Nagel articulates a better objection to physicalism in terms of what is left out of a physicalistic description of the world that does not include token-reflexives. But the use of token-reflexive terms to individuate items has no bearing on what kind of thing it is, or on the nature of the thing. Nor should this fact lead one to deny that a person is an I, a self, or a subject in the sense of being something which has and undergoes psychological states and processes. One can still feel that they occupy a unique and singular point of view, like a fixed point in a turning, changing world. This feeling that something essential and inner about oneself has been left out of a 
physicalistic description of the world is due partly to the elimination of any unique system of reference or point of view. If two people give a complete description of a room in which they are both located, they would give the same description only if they left something out, namely, who is writing the description, because this itself is not part of the description of the room. The sense in which the world is my world would be left out by physicalism.

Another factor that contributes to the view that one's "self" is privileged and occupies a unique point of view is that we seem to have underprivileged access to our own bodies as objects of scientific investigation. My access to my body is not like my accessibility to the bodies of others, or like my access to other material objects. I can see other bodies from many different points of view and inspect them from different distances. But I cannot ordinarily do that with my own body. I experience my own body always from the same point of view and cannot vary my distance from my own body or take a good look from many different angles. My experience of my own body has a constancy and invariability not shared by my experience of any other body. I can only imagine being in the place of another person observing my body the way I observe their body.

We can observe the motion of other things, but not in the same way that we observe the motion of our body. When we are being moved, as when we are riding on a train, we can experience our bodies as moving in relation to other things, and this is much like the way we notice that other bodies are moving. But when we move our bodies, we do not find out that our body is moving by observing it in relation to other things. We can know other bodies are moving by merely observing them, and by watching them trace a continuous path through space, but we cannot do this with ourselves in this same detached way. We can follow other things and people around and observe them continuously from one place to another, but we cannot follow ourselves.

Usually, we know about the movement of other things on the basis of continuous observation or inferences between discontinuous stretches of observation, but this is not usually the way we know that we are moving from place to place. We know about our own movements on the basis of continuous experience and memory, and do depend on observations such as those in a reflected image to experience our own bodies. We also have privileged access our own minds, which encourages us to slide into the view that oneself occupies a unique and privileged point of view not dependent on empirical investigation.

Yet, in some ways, we have a different, inferior access to our body than we do to other bodies. When we do see ourselves as objects of empirical investigation, we connect ourselves with the feeling that our own unique and singular point of view is left out of an empirical description. We may begin 
to believe that we must be more than body. The feeling that the self has been left out of the description results from an asymmetry between our superior empirical access to the bodies of others compared to our own body considered as an object of empirical investigation. There is also an asymmetry between our knowledge of the mental states of others and the knowledge one has of their own mental states. I can know that Jones has a headache only by way of some bodily or behavioral facts about Jones, but I know I have a headache without knowing anything about my body or behavior. My incomplete access to my body as an empirical object can be put alongside of my privileged epistemic access to my states of mind in a way that makes it seem that I cannot possibly be just a body. But this does not by itself show that I am in fact not just a physical thing. It does show it is hard to believe I am just a physical thing.

\section{References:}

Coval, S. Skepticism and the First Person. London: Methuen. (1966).

Nagel, Thomas. "Physicalism.” Philosophical Review, 64, 339-356. (1965).

Russell, Bertrand. An Inquiry into Meaning and Truth. London: Allen and Unwin, 108-116. (1940).

Ryle, Gilbert. The Concept of Mind. New York: Barnes and Noble. (1949).

Smythe, Thomas W. "Self-Knowledge and the Self." Journal of Philosophical Research. 26, 287-294. (2001).

Smythe, Thomas W. "Intuiting the Self." Psychology of Intuition, Bartoli Ruelas and Vanessa Briseno (eds). New York: Nova Science Publishers. (2010).

Smythe, Thomas W., "My body: Is it me?” Open Journal of Philosophy, 2, (3). (2012).

Wittgenstein, Ludwig, Tractatus Logico-Philosophicus. B. F. McGuiness and D. F, Pears (Trans.). Humanities Press. (1921). 